\title{
Erratum: Workers' awareness of alcohol breathalyser test in the workplace and their alcohol consumption patterns
}

\begin{tabular}{|c|c|}
\hline \multicolumn{2}{|c|}{$\begin{array}{l}\text { Authors: } \\
\text { Vusi Mthimkhulu }{ }^{1} \text { (D) } \\
\text { Hugo D. van der Walt }{ }^{2} \text { (D) }\end{array}$} \\
\hline \multicolumn{2}{|c|}{$\begin{array}{l}\text { Affiliations: } \\
{ }^{1} \text { Department of Psychology, } \\
\text { College of Human Sciences, } \\
\text { University of South Africa, } \\
\text { Pretoria, South Africa }\end{array}$} \\
\hline \multicolumn{2}{|c|}{$\begin{array}{l}{ }^{2} \text { Institute for Open and } \\
\text { Distance Learning, College } \\
\text { of Education, University of } \\
\text { South Africa, Pretoria, } \\
\text { South Africa }\end{array}$} \\
\hline \multicolumn{2}{|c|}{$\begin{array}{l}\text { Corresponding author: } \\
\text { Hugo van der Walt, } \\
\text { vdwalhd@unisa.ac.za }\end{array}$} \\
\hline \multicolumn{2}{|c|}{$\begin{array}{l}\text { Dates: } \\
\text { Published: } 20 \text { May } 2022\end{array}$} \\
\hline \multicolumn{2}{|c|}{$\begin{array}{l}\text { How to cite this correction: } \\
\text { Mthimkhulu, V., \& Van der } \\
\text { Walt, H.D. (2022). Erratum: } \\
\text { Workers' awareness of } \\
\text { alcohol breathalyser test in } \\
\text { the workplace and their } \\
\text { alcohol consumption } \\
\text { patterns. SA Journal of } \\
\text { Human Resource } \\
\text { Management/SA Tydskrif vir } \\
\text { Menslikehulpbronbestuur, } \\
\text { 20(0), a1745. https://doi. } \\
\text { org/10.4102/sajhrm. } \\
\text { v20i0.1745 }\end{array}$} \\
\hline \multicolumn{2}{|c|}{$\begin{array}{l}\text { Copyright: } \\
\text { C 2022. The Authors. } \\
\text { Licensee: AOSIS. This work } \\
\text { is licensed under the } \\
\text { Creative Commons } \\
\text { Attribution License. }\end{array}$} \\
\hline \multicolumn{2}{|c|}{ Read online: } \\
\hline 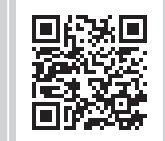 & $\begin{array}{l}\text { Scan this QR } \\
\text { code with your } \\
\text { smart phone or } \\
\text { mobile device } \\
\text { to read online. }\end{array}$ \\
\hline
\end{tabular}

In the original article published, Mthimkhulu, V., \& Van der Walt, H.D. (2021). Wokers' awareness of alcohol breathalyser test in the workplace and their alcohol consumption patterns. SA Journal of Human Resource Management/SA Tydskrif vir Menslikehulpbronbestuur, 19(0), a1627. https://doi. org/10.4102/sajhrm.v19i0.1627, the title contained a spelling error. The first word of the title stated "Wokers" and this was unintentional. As a result of this, the title is corrected to read 'Workers' awareness of alcohol breathalyser test in the workplace and their alcohol consumption patterns'.

The affiliation of the second author was also given incorrectly. The correct affiliation should be 'Institute for Open and Distance Learning, College of Education, University of South Africa, Pretoria, South Africa'.

The publisher apologises for this error. The correction does not change the study's findings of significance or overall interpretation of the study's results or the scientific conclusions of the article in any way. 


\section{Wokers' awareness of alcohol breathalyser test in the workplace and their alcohol consumption patterns}

\begin{tabular}{|c|c|}
\hline \multicolumn{2}{|c|}{$\begin{array}{l}\text { Authors: } \\
\text { Vusi Mthimkhulu }{ }^{1} \text { (D) } \\
\text { Hugo D. van der Walt }{ }^{1} \text { (D) }\end{array}$} \\
\hline \multicolumn{2}{|c|}{$\begin{array}{l}\text { Affiliations: } \\
{ }^{1} \text { Department of Psychology, } \\
\text { College of Human Sciences, } \\
\text { University of South Africa, } \\
\text { Pretoria, South Africa }\end{array}$} \\
\hline \multicolumn{2}{|c|}{$\begin{array}{l}{ }^{2} \text { Institute for Open and } \\
\text { Distance Learning, College of } \\
\text { Education, University of } \\
\text { South Africa, Pretoria, South } \\
\text { Africa }\end{array}$} \\
\hline \multicolumn{2}{|c|}{$\begin{array}{l}\text { Project Research Registration: } \\
\text { Project number: } 35353740\end{array}$} \\
\hline \multicolumn{2}{|c|}{$\begin{array}{l}\text { Corresponding author: } \\
\text { Hugo van der Walt, } \\
\text { vdwalhd@unisa.ac.za }\end{array}$} \\
\hline \multicolumn{2}{|c|}{$\begin{array}{l}\text { Dates: } \\
\text { Received: } 07 \text { Apr. } 2021 \\
\text { Accepted: } 15 \text { June } 2021 \\
\text { Published: } 22 \text { July } 2021\end{array}$} \\
\hline \multicolumn{2}{|c|}{$\begin{array}{l}\text { How to cite this article: } \\
\text { Mthimkhulu, V., \& Van der } \\
\text { Walt, H.D. (2021). Wokers' } \\
\text { awareness of alcohol } \\
\text { breathalyser test in the } \\
\text { workplace and their alcohol } \\
\text { consumption patterns. SA } \\
\text { Journal of Human Resource } \\
\text { Management/SA Tydskrif } \\
\text { vir Menslikehulpbronbestuur, } \\
\text { 19(0), a1627. } \\
\text { https://doi.org/10.4102/ } \\
\text { sajhrm.v19i0.1627 }\end{array}$} \\
\hline \multicolumn{2}{|c|}{$\begin{array}{l}\text { Copyright: } \\
\text { (C) } 2021 \text { The Authors. } \\
\text { Licensee: AOSIS. This wo } \\
\text { is licensed under the } \\
\text { Creative Commons } \\
\text { Attribution License. }\end{array}$} \\
\hline \multicolumn{2}{|l|}{ Read online: } \\
\hline 口Ahiq & $\begin{array}{l}\text { Scan this QR } \\
\text { code with your } \\
\text { smart phone or } \\
\text { mobile device } \\
\text { to read online. }\end{array}$ \\
\hline
\end{tabular}

Orientation: An alcohol breathalyser test is one of various methods of assessing alcohol consumption behaviour of workers in the workplace. Its awareness can yield insights on behavioural change of alcohol-consuming individuals in safety-sensitive settings when being aware of alcohol breathalyser testing.

Research purpose: A breathalyser test provides an efficient means of measuring blood alcohol concentration within seconds of an employee blowing into the device. The purpose of this research was to examine awareness of breathalyser testing to capture meaning that can offer insights on behaviour under research.

Motivation for research: The research was prompted by a quest to gain understanding of thought processes (motivation to control behaviour) when alcohol is involved. By focusing on awareness, it was possible to interpret behaviour. The research is a basis for future studies and can contribute to discussions related to alcohol testing in the workplace.

Research approach/design and method: A qualitative approach was followed to gain insights into the topic under research. Eight alcohol-consuming individuals who performed jobs considered high-risk consented to participate in semi-structured, face-to-face interviews. The data were analysed through interpretative phenomenological analysis (IPA).

Main findings: The findings revealed excessive alcohol consumption and intoxication in spite of awareness of breathalyser testing. Individuals prone to external inducements were more likely to abuse alcohol. Behaviour therefore tends to be unstable and impulsive when alcohol is involved.

Practical implications: Reporting for work after excessive drinking of alcohol is not an indication of total soberness. Individuals may physically be present in the workplace without making any contribution to work processes because of effects of alcohol.

Contribution/value-add: The research highlights behavioural insights that can contribute to studies related to locus of control and control over alcohol in relation to testing to workplace testing.

Keywords: behavioural change; breathalyser testing; effects of alcohol; inducements; locus of control; workplace testing.

\section{Introduction}

\section{Orientation}

Alcohol and drug testing is a modern practice in the workplace, dating back only as early as the 1980s (Besinger, 2017). The rise in workplace testing originated between 1985 and 1991 in workplaces in the USA (Hartwell, Steele, Park, \& Roddman, 1996). The need for testing was brought by the mounting substance-related cases and work-related incidents (accidents, fatalities and absenteeism) associated with alcohol, which had an impact on profitability and sustainability of workplaces (Besinger, 2017). By 1992, alcohol and drug testing in the USA had increased from $18 \%$ to $40 \%$; thus, nearly $77 \%$ of its companies reported making use of alcohol and drug testing in their workplaces (Hartwell et al., 1996). The market for alcohol and drug testing in the USA alone is estimated at over $\$ 2.6$ billion with more than 150 million alcohol and drug tests having been performed in its workplaces (Phifer, 2016). A study aimed at establishing the prevalence of alcohol and cannabis in South African mines found that alcohol use tends to be high among mineworkers in South Africa and Australia (Pick et al., 2003). To illustrate, the prevalence of risky drinking 
among workers in a South African gold mine was found to be $32 \%$ with the majority of those workers in unskilled or semiskilled positions (Kew, 1994 cited in Pick et al., 2003). Another study that examined the consequences of alcohol abuse and cigarette consumption in Mamre (Western Cape) found that the highest rates of alcohol abuse (32\%) as a household problem among unskilled manual workers and the lowest rates $(9.1 \%)$ were among professionals (Yach \& Joubert, 1988 cited in Pick et al., 2003). A study in Namibia that explored the comprehensiveness of alcohol and drug testing in the mining sector found high prevalence rates of alcohol abuse within communities (Maree, Lightfoot, \& Ananias, 2016). Correspondingly, South African Community Epidemiology Network on Drug Use's observation (SACENDU) has found alcohol to commonly abuse in the context of South Africa (Sutherland \& Ericson, 2010). The above insights point to alcohol as both a challenge for the workplace and within communities (Maree et al., 2016; Sutherland \& Ericson, 2010).

Conversely, the mining sector in South Africa tends to regulate alcohol in its workplaces because of hazards associated with the working environment, thus fitting the description of a safety-sensitive workplace. To illustrate, the burden of safety in the workplace lies solely with the employers in this sector; however, workers also accept responsibility for their safety by adhering to safety regulations in the workplace (The Mine Health and Safety Act 29 of 1996). In spite of these stricter regulations, absenteeism seems to cost the South African economy almost R9billion a year (Fourie, 2017). The diamond mining industry alone has reported production losses of nearly R476 525 per shift in 2016, which totalled to nearly R3 967792240 (Fourie, 2017). Subsequently, the production losses in 2017 amounted to R3 400249988 (Fourie, 2017). In general, the mining sector tends to lose 86 working days a year to absenteeism because of alcohol (Fourie, 2017). These findings are a cause of concern as three out of four persons in the workplace consume alcohol (Fourie, 2017). Moreover, the rates of alcohol were found to be predominantly high among unskilled manual workers $(32 \%)$ and professionals $(9.1 \%)$ in the workplace (Yach \& Joubert, 1988 cited in Pick et al., 2003).

\section{Research purpose and objectives}

An alcohol breathalyser test is perceived to be effective in managing alcohol consumption behaviour of workers in the workplace (Hartwell et al., 1996). The purpose of this research was to explore lived experiences of alcohol-consuming individuals and their awareness of breathalyser testing to gain understanding of thought processes that can yield insights on behaviour (control). As discussed in the earlier section, alcohol has a bearing on the workplace in South Africa, particularly in sectors deemed to be safety-sensitive (i.e. mining) where alcohol is restricted (Fourie, 2017; Maree et al., 2016; Pick et al., 2003). The objective of the research was to discover meaning in accordance with the world view of research participants under study (Thanh, Thi, \& Thanh,
2015). The individual accounts of experiences of breathalyser testing therefore laid ground to this social inquiry in pursuit of meaning.

\section{Literature}

An alcohol breathalyser is a device used in alcohol testing procedures, which measures blood alcohol concentration (BAC) by analysing an amount of alcohol in the bloodstream through a breath sample (Swartz, 2004). An alcohol breathalyser test is regarded as less intrusive in comparison to other procedures, which tend to draw blood or make use of urine samples from a worker suspected to be under the influence of alcohol (Bible, 1986). Breathalyser devices are considered more practical and their portability (handheld) makes it easy to administer alcohol tests in the workplace (Workman, 2012). These devices can deliver prompt results in seconds of a worker blowing into the device (Workman, 2012). Alcohol breathalyser devises are therefore expedient, cost-effective and effective in monitoring alcohol in the workplace (Hartwell et al., 1996).

Alcohol is a considerable safety hazard for a workplace deemed to be safety-sensitive, which then permits such companies to institute disciplinary measures as prescribed within employment law in South Africa (Department of Labour of South Africa, 1995) (Department of Labour of South Africa, 1995). Thus, line managers may elect temporary measures (i.e. issuing written warnings) or lasting measures (i.e. rehabilitation or ongoing counselling) in dealing with alcohol in the workplace (Cook, 2014; Hartwell et al., 1996; Johns, 2016). In exceptional circumstances, a worker may be requested by a line manager to use sick leave as justification for absence from work because of alcohol (Maree et al., 2016). In extreme cases, a worker may be dismissed through termination of a contract of employment because of alcohol; in addition, criminal charges may be pursued externally (i.e. magistrate court), showing evidence that the worker concerned was in a safety-critical role (Cook, 2014; Olbina, Hinze, \& Arduengo, 2011). An alcohol breathalyser test is therefore not only essential in detecting workers whose performance may be temporarily or permanently impaired because of alcohol, but also in removing those workers from the workplace because of the risk that they might pose on themselves and others while working in a safety-sensitive working environment (Pidd \& Roche, 2014).

Although alcohol breathalyser devices appear to be useful and convenient for monitoring alcohol in the workplace, problems with inconsistencies in the results of tests are not uncommon with these types of devices. Alcohol breathalysers tend to be inclined to discrepancies because of false positives within the process of testing (Workman, 2012). For example, electrochemical fuelled cells on the mouthpiece of a breathalyser device tend to respond to all members of the alcohol family indiscriminately, which includes thousands of compounds (Workman, 2012). Thus, products that contain alcohol (i.e. medicine or yeast) are likely to report false positives (Workman, 2012). For this reason, a second or third 
test is normally recommended to rule out any inconsistencies in the process of testing for alcohol; however, this practice is not universally applicable and is largely dependent on policies governing each and every particular workplace (Workman, 2012).

\section{Theoretical perspectives underpinning behaviour}

The understanding and interpretation of behaviour under this section was drawn from social learning theory as ascribed by Julian Rotter and later conceptualised the model of locus of control (Beukman, 2005). The capacity of individuals to exercise control over specific events in their lives is seen as either coming from within individuals themselves or coming from the environment (Beukman, 2005). Thus, individuals who attribute control over the events in their lives as coming from within themselves tend to have an internal locus of control and individuals who attribute control to external influences tend to have an external locus of control (Roddenberry, 2007). Locus of control is therefore a point at which an individual is confident in controlling the outcomes of events in life as either coming from within the individual or swayed by external influences (Roddenberry, 2007). According to Roddenberry (2007), beliefs are perceived as a channel to a psychological functioning of an individual. The attributes of an individual are therefore perceived to be shaped by judgements (i.e. beliefs and commitments), which are significant indicators of a persons' psychological functioning (Folkman, 1984 cited in Roddenberry, 2007).

Under this research, it is possible that alcohol-consuming individuals will tend to reduce or abstain from alcohol when off-site because of awareness of breathalyser testing in the workplace. Thus, when individuals believed to have control over situations involving alcohol will likely reduce or refrain from alcohol, which indicate internal locus of control (Roddenberry, 2007). The event that individuals believed to have no control over these specific situations because of factors in the environment and thereby getting intoxicated is an indication of external locus of control (Roddenberry, 2007). It is, however, important to note that within the concept of locus of control, internality and externality symbolise two ends of a continuum, and not an either/or classification because there is another type of control that involved a mix of internal or external types. Individuals with combination types tend to take personal responsibility for their actions while still able to attribute control to external influences.

An experiment in the USA has found that safety-related incidents in the workplace to be linked directly to mistakes made by workers (Wuebker, 2011). The experiment implemented a safety-locus-of-control scale, which divided workers likely to be at risk of unsafe behaviours at work (i.e. accidents and injuries) into two groups categorised low accident group and high accident group. The scale then assessed the risk factors through variables labelled internally orientated and externally orientated behaviours. The hypothesis was that internally orientated individuals would exhibit a tendency to show an association between personal behaviour and the outcome (risky behaviours). The data revealed that workers in low accident group demonstrated more internal orientation in their safety locus of control beliefs in comparison with workers in the high accident group (Wuebker, 2011). Thus, the more internally orientated the group was, the lower the risks were associated with accidents (Wuebker, 2011). The above experiment therefore showed that locus of control was significant in shedding behavioural insights that can significantly contribute to the workplace. The concept of locus of control was therefore deemed fit to interpret and explain behaviour under this research.

\section{Research design Research approach}

This research process adopted an interpretivist paradigmatic qualitative approach by exploring detailed accounts of research participants regarding a specific phenomenological experience (Gough \& Lyons, 2016). Face-to-face interview was the only vehicle to gain access to rich and in-depth accounts of the phenomenon reported under this research (Smith, Flowers, \& Larkin, 2012). A qualitative interpretivist stance was deemed to be fit to capture lived experience and the essence of meaning as told by research participants (Thanh et al., 2015).

\section{Research strategy}

Face-to-face interviews provided an occasion to explore indepth understanding of the phenomenon under research (Smith et al., 2012). This approach enabled a dialogue in real time between the researcher and research participants to achieve a conversation with a purpose in accordance with research aims (Smith et al., 2012). In addition, this approach enabled contact with research participants thereby adding a human component in the process of research, which assisted in capturing meaning by taking cognisant the emotions and feelings of research participants. These insights were incorporated into the analysis to deliver the richness of lived experiences (Smith et al., 2012).

\section{Research method}

The study is exploratory and seeks to gain new understanding of a topic under research (Mayer, 2015). This research seeks to make a contribution towards discussions related to alcohol consumption behaviour in relation to alcohol testing in the workplace, and lays groundwork for future studies. The exploratory method was therefore fit for purpose because the research intent was not only to articulate concluding proof of the phenomenon under research, but also to lay ground for further studies within this particular field (Mayer, 2015).

\section{Research setting}

Data were collected in different parts of Johannesburg and Midvaal, South Africa. These areas are located close to 
industrial sites (manufacturing, chemical, steel and mining) where safety-sensitive companies tend to employ people from nearby communities.

\section{Entrée and establishing researcher roles}

The first researcher is a postgraduate student and a lecturer in the Department of Psychology at the University of South Africa in Pretoria, South Africa. The second researcher is an academic staff member at Open and Distance Learning (IODL), University of South Africa in Pretoria, South Africa. The first researcher collected the data, analysed and interpreted it while the second researcher supervised and assisted in interpreting and structuring the research.

\section{Research participants and sampling}

The sample consisted of eight male individuals between ages of 32 and 60 who indicated that they were inclined to alcohol consumption outside working hours, performed tasks at work that were considered high-risk and were frequently exposed to alcohol breathalyser testing at work. The sample is in accordance with interpretative phenomenological analysis (IPA) studies where participants have shared experiences of a phenomenon in a specific context (Burr, King, \& Butt, 2014; Smith, Flowers, \& Larkin, 2012). A purposive snowball sampling technique was employed, which involved asking those who have already been approached to be part of the research if they knew other individuals who may be interested in taking part in research (Smith et al., 2012).

\section{Data collection}

The interviews were face-to-face and semi-structured through an interview guide, which assisted in capturing the dialogue in real time in three different languages preferred by individuals under research (i.e. IsiZulu, Sesotho and English). An interview guide consisted of 19 questions divided into five sections (i.e. parts A-E). The structure of questions included closed questions (7) and open-ended (12) questions. The open-ended questions encouraged the participants to deliver detailed information under the discussion and allowed the researcher to pursue meaning. The closed questions included prompts to encourage engagement and bolster the conversation, which is consistent with IPA approach to assist with the flow of an interview process (Smith et al., 2012). The questions were formulated with consideration of behaviour as a point at which individuals felt encouraged and confident in controlling situations involving alcohol or otherwise felt discouraged because of influences in the environment (Beukman, 2005; Roddenberry, 2007).

\section{Strategies employed to ensure data quality and integrity}

The research ensured scientific rigour through credibility, dependability, transferability and confirmability (Zhang \& Wildemuth, 2005).

\section{Credibility}

This research achieved credibility through constant interaction between the authors of this research on coding methods to ensure that the themes were efficiently drawn from raw data and represented the experiences and perceptions of the sample. In addition, the second researcher is a trained and certified senior ATLAS.ti software trainer and coder.

\section{Transferability}

In this research, transferability was achieved through the interpreted analysis of the data from ATLAS.ti. The raw data and the printed transcripts are available for audit or further research purposes (within the limits of ethical consideration discussed in the consent form). The availability of the coding methods in analysing data to deduce meaning also provides a basis to which other researchers could make their own conclusions about the findings of the research.

\section{Dependability}

The transcribed interviews, field notes, reflective notes from the notebook and the codebook can be available on request in the event of an audit trial, thus ensuring dependability.

\section{Confirmability}

In this study, the substantiation of field notes, interpretative notes from the codebook, the coding process followed as well as the appendices to the research are kept in a safe place for audit purposes.

\section{Data analysis}

Data analysis involved the application of an IPA approach that is concerned with the appreciation of language in interpreting messages that simplify experiences and perceptions of the world as seen by individuals under research (Smith et al., 2012). Congruently, the IPA approach is regarded as a well-established approach to study a range of psychological topics (Smith et al., 2012). The analysis process involved identifying patterns among emergent themes from data and developing them into superordinate and subordinate themes using ATLAS.ti software. The themes belonging together were clustered and reduced into meaning according to the lived experiences and perceptions of the individuals under discussion. The collated codes and themes were further cross-checked and discussed until consensus was reached by researchers. ATLAS.ti assisted in analysing the complex phenomenon hidden in the data through its contemporary data analyses tools.

\section{Reporting style}

Three major themes were identified in relation to awareness of alcohol breathalyser testing while consuming alcohol outside work contexts. The themes focused on aspects of behaviour in accordance with the literature under research. 
The findings were reported according to themes with each finding backed by direct quotations from the individuals within research.

\section{Ethical considerations}

Information sheets and consent forms provided in-depth details of the research prior to participation in the research process. The information included the right to participate or withdraw (voluntarily), privacy and confidentiality, limitation of anonymity and risks to potential harm during the course of research. The authors applied for permission from the Ethics Committee of the University of South Africa (Unisa), Department of Psychology (Ref No: PERC-17401). Pseudo names (P1-P8) were employed to protect the identities of research participants.

\section{Results}

Three major themes emerged during data analysis: (1) reaction to awareness of breathalyser testing (when consuming alcohol), (2) perceptions of control and (3) personal meaning of lived experiences. These themes are discussed in detail in the following section.

\section{Reaction to awareness of breathalyser testing (when consuming alcohol)}

By emphasising awareness (alertness) under this section, it was possible to gain insights into individuals' thoughts and interpretations (cognitive occurrences) in their own understanding (meaning) to interpret and analyse behaviour. Under this theme, individuals reported ceasing the use of alcohol; however, the ceasing of alcohol use transpired very late in spite of the awareness of breathalyser testing. The excerpts of data below highlight these instances transpiring with awareness of breathalyser testing:

'From 12 o'clock midnight, if you were drinking the whole of Sunday. Now, I'm actually supposed to be preparing myself for work and I am aware of the consumption, and then I am aware of tomorrow around 07:00 I will be tested.' (P1)

'Ten o'clock (22h00) I have stopped consuming alcohol, I'm always aware.' (P2)

'So it's up to me that at 4 or 6 o' clock in the afternoon, I stop.' (P6)

The behaviour highlighted above is a cause of concern because safety-sensitive workplaces tend to have shift work patterns that commence between 07:00 and 19:00 at any given 24-h day (Health Safety Executive, 2006). The overlap in excessive drinking of alcohol (until very late) and job demands (to reporting early for work) culminated to absenteeism from the workplace because of effects of alcohol. The quotations below point to this behaviour:

'I feel that I am really drunk, I must not go to work. I will not go to work.' (P3)

'You tell yourself that tomorrow you're not going to work.' (P4)

'Tomorrow you try to wake up, the head is heavy, agh no. I'm not going to work. You just tell yourself that you are bunking.' (P6)
Data revealed incidences of dishonest behaviour carried out to justify absences from the workplace because of effects of alcohol. This behaviour concurred with the description of absenteeism as unauthorised absences from work for any reasons other than illness (Fourie, 2017):

'On Monday, I just have to go to a doctor and lie. Maybe you go to a doctor you get a letter for 1 day.' (P4)

'At the doctor there's no this thing that you're drunk, sometimes we tell them that I didn't go to work because of $1 \ldots 2 \ldots 3$ (other reasons not related to intoxication) and he writes you a letter that you will present that you were not okay.' (P8)

'You ask for those 3 days, while at home.' (P6)

Under this theme, the results have shown that seizing alcohol consumption transpired very late (from 16:00-12:00) when individuals have already reached intoxication. In addition, individuals confirmed that they were aware of breathalyser testing all the while consuming alcohol. In terms of data, the stoppage of alcohol was therefore unrelated to awareness of breathalyser testing because alcohol ensued to a level of intoxication despite this seeming awareness.

\section{Perceptions of control}

Data under this theme revealed instances when individuals felt confident and believed to be in control by refraining from alcohol. This behaviour was interpreted as internal locus of control because self-confidence emanated from within the individuals under research, thus maintaining control over specific events in life (Beukman, 2005; Roddenberry, 2007). The researchers noted that control over situations specified below was unrelated to awareness of breathalyser testing according to data excerpts:

'You are able to; they [friends] will drink while you're just sitting there. Sometimes I just want their company, I don't want to drink.' (P6)

'You channel your mind into other things that excite you, like music.' (P1)

'I could have a wonderful and a great time without consuming any alcohol. I'll say it actually helps a bit [breathalyser], but like I said, in my case it's not really a concern.' (P2)

Data also revealed instances where challenges with maintaining control over certain events were encountered because of inducements external to individuals (i.e. drinking peers and entertainment). This behaviour was interpreted as external locus of control because individuals believed that they had little or no control over certain events in life (Beukman, 2005; Roddenberry, 2007). Correspondingly, a study conducted in Australia that assessed problematic drinking behaviour; the levels of alcohol consumption, restrained drinking and cognitive control found that dedicating considerable strength (i.e. cognitive effort) to managing an emotion can exhaust or drain coping resources (Williams \& Ricciardelli, 1999). Thus, in the case of alcohol consuming behaviour, the signals to drink are more likely to override the intentions to drink less or abstain from alcohol (Williams \& Ricciardelli, 1999). Data in this research 
concurred with this understanding that cues to drink alcohol tended to dominate the intentions to drink less or refrain from alcohol as specified in Williams and Ricciardelli (1999). The excerpts below point out such behaviour:

'It's difficult because the people who invited you will always want to offer you something to drink.' (P2)

'We enjoyed ourselves, and I forgot about my work. There is no one who will block you. You are happy for each other isn't.? It becomes so nice.' (P7)

'It is because of enjoyment, when you check your time, it is already late.' (P3)

'The vibe [entertainment] where you are it would be lit [abuzz].' (P4)

Overlapping with behaviours stated above were consumption of alcohol on Sundays, which individuals highlighted as challenging because of external inducements (i.e. drinking peers and entertainment) which is more prominent on Sundays:

'Sunday was too hectic for me, it seems like alcohol becomes very nice. It's difficult to control yourself, mostly I drink beer, sometimes if I drink whisky, I forget myself, when I look it's already late and now I'm mixing [beer] and whisky. Then when your friend arrives, he gets 4 [beers] and puts it here, you see, it's difficult.' (P8)

'There are instances like that, where you feel like okay, I drank over or maybe I don't even know when I'm drunk.' (P1)

'It is fun, and alcohol on a Sunday becomes more delicious.' (P6)

The behaviours highlighted above were congruent with a method of control labelled retrained. Restrained is characterised by rigid control intermingled with sessions of self-indulgence (i.e. bingeing); thus, it was found to be a counteractive method (Williams \& Ricciardelli, 1999). In the context of this research process, those behaviours were interpreted as external locus of control because of control attributed to external influences (Beukman, 2005; Roddenberry, 2007). Data revealed that these periods of excessive alcohol consumption were followed by drinking certain remedies believed to offset the effects of alcohol. The individuals believed that these remedies were effective in offsetting the effects of alcohol despite the information that alcohol measuring instruments can detect alcohol on the breath for up to $24 \mathrm{~h}$ after its consumption (Wagener, 2021). The quotations below are from the individuals: however, they were uncomfortable in discussing these remedies in detail:

'There's a medication that they take, when we test your alcohol it won't show. He knows that in the morning when I go to work, I will do $[1,2 \ldots$ referring to instructions on the use of this medication] When they test me it won't show.' (P5)

'Others believe that when they are drunk, they should vomit in the morning. Like those who drink almost every day.' (P5)

'I know that when I wake up in the morning, maybe I have to drink something and vomit it to cleanse myself, but I have to do something about the alcohol in my system.' (P3)

Data indicated that the individuals were cognisant of the effects of alcohol, but nevertheless, went to the workplace (considered to be safety-sensitive) to perform jobs regarded as high-risk. Below are individuals' quotations from data:

'So if you stop around $10(\mathrm{pm})$ there's a possibility that it's already morning, already you are waking up to go to work. That thing will still be there, because if you stop at around $10(\mathrm{pm})$ most of the times in the morning you will suffer hangover.' (P5)

'It's there but you know there's something called a hangover, it's yesterdays', you're not drunk it's yesterdays.' (P6)

'But the water consumption is just for me to like to try and not really be babalas in the morning.' (P2)

The results were consistent with the practice of a second and/ or third alcohol test employed to minimise inconsistencies in the results of tests (Workman, 2012). Data showed that the beliefs about control were resilient despite the results of tests indicating the presence of alcohol that was not related to medicine or yeast:

'Sometimes it reduces, sometimes it rises, and sometimes it vanishes from your body, like maybe its yesterday's alcohol.' (P5)

'First test, second test is to show us the alcohol you consumed, like you say it may happen that people drink in the morning, it rises. When it reduces, we know at least they may allow you at the company, maybe you stay there so that after maybe 3, 2 hours you eat because they need you inside.' (P5)

The results under this theme showed the challenges regarding control, especially when alcohol is involved. The drinking of unspecified medicines was interpreted as feelings of regret after excessive alcohol drinking and perhaps transpiring with sense of responsibility, hence efforts to regain control and attempting to go to the workplace despite alcohol effects. The inconsistencies in testing results (i.e. second to third testing) seemed to assure the individuals of some level of control despite suffering from the effects of alcohol. This behaviour was interpreted in accordance with mixed types locus of control because, on the one hand, individuals took personal responsibility for their actions (i.e. attempting to go to the workplace after excessive alcohol drinking); and, on the other hand, still relied on external resources (i.e. second or third tests) (International Journal of Indian Psychology Inc., 2014).

\section{Personal meaning of lived experiences}

The IPA method allows individuals to reflect on their experiences of the phenomenon under research (Smith et al., 2012). Thus, the way in which individuals describe what is occurring in their lives tends to shed light on the meaning attached to those experiences regarding a phenomenological experience (Gough \& Lyons, 2016). The meaning of experiences was therefore significant in appreciation of thoughts, emotions and behaviour of participants within this research process (Burr et al., 2014). The interpretation of how the individuals viewed what was happening in their lives was in accordance with their meaning they ascribe to it (Thanh et al., 2015). The data excerpts highlight individuals' accounts as told by them: 
'I would say as an individual the issue of tests is not fine, but it has to be done in firms. It is right.' (P7)

'People shouldn't perceive being tested for alcohol at the workplace as a negative thing; is a positive thing. There's a lot of good that comes out of it.' (P2)

Data indicated that individuals believed that the absence of alcohol breathalyser testing in the workplace would lead to total loss of control in behaviour. The sentiments expressed regarding alcohol testing seemed applicable in both work and personal contexts according to data below:

'I stopped drinking, because of this testing thing.' (P6)

'I love it, it protects me, I work with things that are very dangerous, and I won't be compromised like that. They can test me ten times a day, I wouldn't mind.' (P2)

'Factories are not made for alcohol. So I think that this thing of making people blow is a good thing. It should not only be in factories, even at municipal offices and schools it should be done.' (P4)

Results under this theme illuminated individuals' accounts of acceptance of breathalyser testing as part of everyday existence in that it has changed lives; and thus, viewed in a positive light. The impression that testing should be made public policy emphasised the significance of breathalyser testing in the context of this research. However, the confidence in breathalyser testing to regulate alcohol consumption behaviour may be limiting; and thus, undercut the importance of learning other ways of managing behaviour such as beliefs and commitments (internally orientated), which tend to hold significant meaning (Roddenberry, 2007).

\section{Discussion}

The results have shown consumption of alcohol until early hours of the next working day with full awareness of impending breathalyser testing in the workplace. This finding raised a concern because the working shifts in safetysensitive work settings tend to start as early as 07:00 to 19:00 (Health Safety Executive, 2006). In addition, alcohol testing devices are perceived to be proficient in measuring alcohol in the bloodstream for up to $6 \mathrm{~h}$ and on the breath for 12-24 h (Wagener, 2021). Sleep deprivation overlapping with effects of alcohol may be a hazard for high-risk jobs in work settings considered safety-sensitive. Moreover, it has been shown that work-related incidents (i.e. accidents and fatalities) were because of mistakes made by workers as opposed to the dangerous equipment in the workplace because of alcohol (Fourie, 2017; Olbina et al., 2011; Wuebker, 2011).

The results point to awareness of alcohol breathalyser testing as less likely to discourage alcohol consumption in the context of this research. In addition, consumption of alcohol tends to ensue despite the possibility of dismissal from the workplace in the event that alcohol is detected through breathalyser testing. Conversely, the notion of 'yesterday alcohol' created a misconception of control to the individuals under study. The drinking of unspecified medicines contributed to misdirected beliefs about control. In spite of these flaws in cognitive thinking (i.e. perception), beliefs regarding control remained concrete. This insight was congruent with a view that beliefs were significant indicators of a person's psychological functioning (Folkman, 1984 cited in Roddenberry, 2007).

The results stressed the significance (meaning) of alcohol breathalyser testing in the context of this research. Breathalyser testing may have changed lives (i.e. permanent sobriety), and this total reliance may signal difficulties in adjusting behaviour. This understanding agrees with the view that the more life experiences an individual has in building up a set of beliefs, the more self-control and involvement it would be required for a change in behaviour to transpire (Mearns, 2014). Thus, learned behaviours and persevered attitudes can be resistant to change (Mearns, 2014). The reliance on breathalyser testing is therefore problematic in this regard. However, as with an interpretivist approach, the exploration of the human experience is viewed as value-bound and value-laden (Schwandt, 2001 cited in Wagner, Kawulich, \& Garner, 2012). Therefore, data analysis in this research took cognisant of the significance (meaning) of values of the research participants within the research (Wagner et al., 2012). The interpretation of meaning was without judgement of lived experiences of individuals under this research because in IPA research, there are no wrong or right values, but different values (Tam, 2016).

\section{Limitations and recommendations}

The sample dominated by men with shop floor and engineering backgrounds within safety-sensitive work settings in spite of gender not being an emphasis of this research. In addition, snowballing sampling technique was employed to attract a diverse and representative sample of research participants interested in taking part in the research; however, it was not possible to attract a representative sample. This challenge is therefore considered a limitation because of safety-sensitive industries dominated by men. Future research can therefore endeavour to close this gap through rigorous sampling methods. In addition, the research is based on data collected from Johannesburg and Midvaal, which is a limitation. The results could therefore not be generalised.

\section{Conclusion}

The researchers concluded that behaviour tends to be unstable and impulsive when alcohol is involved. A breathalyser test alone may therefore be impractical to monitor alcohol consumption behaviour on and off the job. Self-regulating behaviour is complex when alcohol is involved; moreover, when the inducements in the environment tend to be overpowering. For that reason, alcohol-consuming workers are likely to be in the workplace without adding any value to the work processes because of suffering from the effects of alcohol. Beliefs that 'its yesterday's alcohol' is not only unscientific, but a hazard for work settings considered safety-sensitive. Although not proposed as the panacea to wiping out alcohol in the workplace, it may be prudent that any detected alcohol on the breath of a worker should be a cause for an investigation that precludes entry to the work area in spite of the operational or production demands. Thus, a second or third breathalyser test should be reserved only for medically related reasons 
backed by a written medical document that a worker concerned can perform only light duties in the workplace for a specified period of time. Moreover, it has been shown that medicine (not alcohol) tends to complicate testing results when making use of breathalyser devices (Workman, 2012). Medically related reasons should therefore be the only authorisation for a second or third test as opposed to dedicating efforts to re-establishing alcohol levels in the breath of workers who may be inebriated or suffering from effects of alcohol while on duty. The onus to proof that the BAC reflected on the breathalyser device is medically related, and not from stale alcohol should shift to workers. This approach can therefore compel workers to accept responsibility and commitment to safety in the workplace. This practice may reinforce zero tolerance for alcohol in the workplace. This research was not able to establish the influence of alcohol on safety and performance in the workplace. Future studies should endeavour to close this gap to contribute to the debate.

\section{Acknowledgements Competing interests}

The authors have declared that no competing interest exists.

\section{Authors' contributions}

V.M. drafted the article from the field research supervised by H.D. and H. D. V.d.W. also contributed to editing and refining the article prior to submission.

\section{Funding information}

This research received no specific grant from any funding agency in the public, commercial or not for profit sectors.

\section{Data availability}

The data for this particular study are restricted to accessibility on granting permission from the University of South Africa. Special permission should be granted from the institution to gain access to data.

\section{Disclaimer}

The views and opinions expressed in this article are of the authors and do not necessarily reflect the official policy or position of any affiliated agency of the authors.

\section{References}

Besinger, P.B. (2017). Drug testing in the workplace. The Annals of the American Academy of Political and Social Science, Vol. 498, The Private Security Industry: Issues and of Political and Social Science, Vol. 498, The Private Security Industry: Issues
Trends (July 1998), 498, 43-50. https://doi.org/10.1177/0002716288498001005

Beukman, T.L. (2005). The effect of selected variables on leadership behaviour within the framework of a transformational organisation paradigm. Pretoria: University of Pretoria.
Bible, J.D. (1986). Screening workers for drugs: The constitutional implications of urine testing in public employment. American Business Journal, 24(3), 309-357. https:// doi.org/10.1111/j.1744-1714.1986.tb00501.x

Burr, V., King, N., \& Butt, T. (2014). Personal construct psychology methods for qualitative research. International Journal of Social Research Methodology, 17(4) 341-355. https://doi.org/10.1080/13645579.2012.730702

Cook, N. (2014). Health focus. The RoSPA Occupational Safety \& Health Journal, April, 13-17. Labour Relations Amendment Act, Pub. L. No. 38512, 412 (1995).

Department of Labour of South Africa. 1995. Labour Relations Act No.66 of 1995

Fourie, R. (2017). Fatigue, substance use and sick leave of employees in a mining environment (Issue May). Potchefstroom: North-West University.

Gough, B., \& Lyons, A. (2016). The future of qualitative research in psychology: Accentuating the positive. Integr Psych Behav, 50, 234-243. https://doi. org/10.1007/s12124-015-9320-8

Hartwell, T.D., Paul D.S., Michael T.F., \& Nathaniel, F.R. (1996). Prevalence of Drug Testing in the Workplace. Monthly Labor Review, 119(11), 35-41.

Health Safety Executive. (2006). Managing shiftwork - Health and safety guidance. HSE Books (pp. 1-45). London: Crown Business.

International Journal of Indian Psychology Inc. (2014). The International Journal of Indian Psychology. The International Journal of Indian Psychology, 1(3). Retrieved from https://books.google.co.za/books/about/The_International_Journal_of Indian_Psyc.html?id=qbbfCwAAQBAJ\&source=kp_cover\&redir_esc $=y$.

Johns, D.V. (2016). The National Labor Relations Board's Misapplication of Weingarten Rights to Employer Substance Abuse Testing Programs. Labor Law Journal, 67(1), 285-297.

Maree, M., Lightfoot, E., \& Ananias, J. (2016). A comprehensive alcohol and drug testing policy in the workplace as an intervention in the mining sector. Journal for Studies in Humanities and Social Sciences, 5(1), 1-8. Retrieved from https://www. researchgate.net/publication/307924743_A_comprehensive_alcohol_and_drug testing_policy_in_the_workplace_as_an_intervention_in_the_mining_sector

Mayer, I. (2015). Qualitative research with focus on qualitative data analysis. International Journal of Sales, Retailing and Marketing, 4(9), 53-68.

Mearns, J. (2014). Julian B. Rotter (1916-2014) (Issue October 1916). Thousand Oaks, CA: Sage

Olbina, S., Jimmie, H., \& Christopher, A. (2011). Drug Testing Practices in the US Construction Industry in 2008. Construction Management and Economics, 29(10), 1043-1057. https://doi.org/10.1080/01446193.2011.631553

Phifer, R. (2016). A sensible approach to workplace drug testing for cannabis. Journal of Chemical Health \& Safety, 24(2), 34-38. https://doi.org/10.1016/j.jchas.2016.06.004

Pick, W., Naidoo, S., Ajani, F., Onmukwe, V., Hansia, R., \& Biele, O. (2003). Prevalence of alcohol and cannabis use and reported knowledge, attitudes, and practices regarding its relationship with health and safety on mines in South Africa. Retrieved n.d. from http://hdl.handle.net/10204/1277

Pidd, K., \& Roche, A.M. (2014). How effective is drug testing as a workplace safety strategy? A systematic review of the evidence. Accident Analysis and Prevention 71, 154-165. https://doi.org/10.1016/j.aap.2014.05.012

Roddenberry, A.C. (2007). Locus of control and Self-efficacy: Potential mediators of stress, illnes, and utilization of heath services in college students. Doctoral dissertation (Open Access)

Smith, J., Flowers, P., \& Larkin, M. (2012). Interpretative phenomenological analysis, theory, method and esearch. London, England: SAGE.

Sutherland, M.E., \& Ericson, R. (2017). Abuse, and treatment in people of African descent Journal of Balck Studies, 41(1), 71-88. https://doi.org/10.1177/0021934708331169

Swartz, J. (2004). Breath testing for prosecutors: Targeting hardcore impaired drivers. American Prosecutors Research Institute. Alexandria, VA.

Tam, C. (2016). Investigating the experiences of special school visual arts teachers: An illustration of phenomenological methods and analysis. Indo-Pacific Journal of
Phenomenology, 16(October), 1-11. https://doi.org/10.1080/20797222.2016.1208031

Thanh, N.C., Thi, T., \& Thanh, L. (2015). The interconnection between interpretivist paradigm and qualitative methods in education. American Journal of Educational Science, 1(2), 24-27.

The Mine Health and Safety Act No 29, Pub. L. No. 29, 3 (1996).

Wagener, D. (2021). How long does alcohol stay in your system? Americanaddictioncenters.Org. Retrieved from https://americanaddictioncenters. org/alcoholism-treatment/how-long-in-system

Wagner, C., Kawulich, B., \& Garner, M. (Eds.). (2012). Doing social research: A global context. Berkshire: McGraw-Hill Education.

Williams, R.J., \& Ricciardelli, L.A. (1999). Restrained drinking and cognitive contro among adolescents. Adolescence, 34(135), 557-565.

Workman, T.E. (2012). The science behind breath testing for ethanol. UMass Law Review, 2(110), 110-180.

Wuebker, L.J. (2011). Safety locus of control as a predictor of industrial accidents and injuries. JSTOR, 1(1), 19-30. https://doi.org/10.1007/BF01014164

Zhang, Y., \& Wildemuth, B.M. (2005). Qualitative Analysis of Content. Human Brain Mapping, 30(7), 2197-2206. 